\title{
Eros colado à pele: dialogia entre profundidade $e$ superfície na poesia de Luís Miguel Nava
}

\section{Eros inherent to the skin: a dialogue between depth and surface in Luís Miguel Nava's poetry}

Rodolpho Amaral ${ }^{1}$

\begin{abstract}
Resumo:
A elaboração de um breve percurso nas áreas da Filosofia, Psicanálise e Estudos Literários para pensar a pele em sua relação paradoxal vista em muitas dicotomias, mas resumida no par superfície/profundidade, é um dos motes deste trabalho. Intenta-se, inicialmente, restituir a importância da superfície da pele e demonstrar sua dialogia com o profundo. Para isso, convocam-se os estudos de Ferraz (2014), Anzieu (1989), Merleau-Ponty (1999) e Birman (1999), a fim de sedimentar a pele na constituição do ser, incluindo sua formação erótica. A seguir, procura-se alinhavar a teoria e os conceitos acerca da pele na poesia de Luís Miguel Nava, prenhe em temáticas ligadas ao corpo que privilegiam a porosidade da pele como transcrição da realidade, bem como a inserção do eros - notadamente homossexual - na composição dos poemas. Para esse segundo momento, são basilares os estudos de Pucheu (2011), Martelo (1998), Sales (2018). Assim, cogita-se demonstrar a centralidade da pele na poesia naviana.
\end{abstract}

Palavras-chave: Luís Miguel Nava. Pele. Porosidade. Superfície/Profundidade. Poesia.

Licenciado em Letras (Português/Literaturas) pela Universidade Federal Rural do Rio de Janeiro (UFRRJ) com período sanduíche na Faculdade de Letras da Universidade de Coimbra (FLUC/UC), o que lhe rendeu, ao final de dois anos de intercâmbio, uma dupla diplomação. Mestrando do Programa de Pós-Graduação em Estudos de Literatura da Universidade Federal Fluminense (UFF), subárea Literatura Portuguesa e Literaturas Africanas de Língua Portuguesa. Bolsista CAPES. E-mail: rodolph.amaral@gmail.com 


\begin{abstract}
:
The elaboration of a brief path in the areas of Philosophy, Psychoanalysis and Literary Studies to think about the skin in its paradoxical relationship seen in many dichotomies, but summarized in the surface / depth pair is one of the motives of this work. Initially, the intention is to restore the importance of the skin surface and demonstrate its dialog with the deep. For that, the studies of Ferraz (2014), Anzieu (1989), MerleauPonty (1999) and Birman (1999) are called on, in order to sediment the skin in the constitution of being, including its erotic formation. Next, we try to baste the theory and concepts about the skin to the poetry of Luis Miguel Nava, full of themes related to the body and that privilege the porosity of the skin as a transcription of reality, as well as the insertion of eros notably homosexual - in the composition of the poems. For this second moment, the studies of Pucheu (2011), Martelo (1998), Sales (2018) are essential. Thus, it is considered to demonstrate the centrality of the skin in the naval poetry.
\end{abstract}

Keywords: Luís Miguel Nava. Skin. Porosity. Surface/Depth. Poetry.

A pele goza de um status dúbio em várias áreas do conhecimento, campos do saber que vão da Psicanálise aos Estudos Literários. Ferraz (2014), no arguto ensaio sobre o estatuto paradoxal da pele e cultura contemporânea, diz que "a pele é meio de comunicação por excelência, verdadeira interface dentro/fora, membrana de trânsito e trocas com o que costumamos chamar de "meio ambiente"' (FERRAZ, 2014, p. 62). A autora destaca, ainda, uma visão em que o interior não difere do exterior, produzindo a pele, portanto, uma dimensão contínua, um contínuo indiscernível.

Indo na mesma direção em defesa de um órgão que não apenas serve como invólucro, capa, revestimento do corpo orgânico, o filósofo José Gil rasura ainda mais essa noção da pele e traz à tona a conexão superfície/profundeza no que tange de mais sensível a esse órgão extenso - o toque: 
Lembremos que a pele não é uma película superficial, mas que tem uma espessura, prolonga-se indefinidamente no interior do corpo: é por isso que a sensação de tato se localiza a alguns milímetros no interior da pele, e não à sua superfície (GIL, 2001, p. 76 apud FERRAZ, 2014, p. 62).

É passível de retorno, já nesses fragmentos citados, a presença de dicotomias que reduzem a pele a um elemento do par e congelam sua circulação; ei-los: dentro/fora, interno/externo, raso/fundo, superfície/ profundidade. A sensação de toque à qual se refere José Gil (apud FERRAZ, 2014) serve-nos como um indicativo do prolongamento da pele para dentro, de forma que o filósofo resgatará, nesse órgão, o termo volume. Notemos como Gil desloca as simplificações espaciais acerca da pele e introduz esse vocábulo - volume -, tão importante para o propósito deste trabalho e que será desdobrado ao longo de sua confecção:

[...] esta zona fronteiriça tem realmente uma interface paradoxal: por um lado limita-se por fora graças à pele; por outro, prolonga o espaço da pele para dentro, conferindo à pele um espaço que a contínua, transformando-a: não é já superfície, mas "volume" ou, mais exatamente atmosfera (GIL, 1997, p. 155 apud FERRAZ, 2014, p. 62).

Ainda a respeito de reconfigurações espaciais, Maurice MerleauPonty, na célebre obra Fenomenologia da Percepção (1999), afirma que a profundidade é a mais existencial das dimensões, porquanto revela instantaneamente o elo do sujeito com o espaço (MERLEAU-PONTY, 1999, p. 360), ou seja, "porque afirma a minha existência corporal ou a perspectiva espacial do corpo diante do mundo" (MANZI FILHO, 2007, p. 34).

Numa outra abordagem, mas dando à pele o protagonismo que 
merece, Anzieu (1989) recorrerá a esse órgão para elaborar questões importantes que, até os dias atuais, servem de direcionamento para toda a clínica da Psicanálise. Levando em conta o sentido metafórico da pele, o autor adverte que o conceito criado por ele - o Eu-pele - é uma figura de linguagem que aborda a constituição do Eu tanto na dimensão biológica quanto na dimensão cultural. $O$ conceito explora a vertente que põe em evidência as relações entre o aparelho psíquico e o corpo orgânico (DURSKI; SAFRA, , 2016, p. 106-107). Anzieu designa o Eu-pele como:

\begin{abstract}
uma representação de que se serve o Eu da criança, durante as fases precoces de seu desenvolvimento, para se representar a si mesma como Eu que contém os conteúdos psíquicos, a partir de sua experiência da superfície do corpo. Isto corresponde ao momento em que o Eu psíquico se diferencia do Eu corporal [...] (ANZIEU, 1989, p. 61).
\end{abstract}

A dimensão da pele é tão importante que o conceito cunhado por Anzieu (1989) vem de uma experiência clínica em que observou o sentimento de esvaziamento dos pacientes como consequência da confusão entre os limites do corpo, a imagem do contorno de si mesmo (do $\mathrm{Eu}$ psíquico e do corpo que possui) - o qual o autor d' $O$ eu-pele chamou de "patologias do envelope" (ANZIEU, 1989, p. 88). Anzieu então inferiu que o início da formação do psiquismo "está particularmente relacionado à ideia de 'bolsa', 'contorno', 'continente', 'capa protetora', enfim, pele" (DURSKI; SAFRA, 2016, p. 109). Estando a pele na centralidade da formação psíquica do sujeito, reforçamos nosso intuito de elaborar a habitação desse órgão nos dois termos das dicotomias. Nesse contexto, além do contato com a profundidade dos outros órgãos que a pele reveste, teor material e palpável da relação, temos visto, com Anzieu (1989), uma ligação mais profunda e abstrata que a pele sustém: a constituição do Eu psíquico.

Ainda que o propósito deste trabalho não seja o de examinar a 
pele na clínica psicanalítica, essa digressão é necessária para, à frente, entrarmos no universo poético de Luís Miguel Nava, visto que entender as dinâmicas da pele propicia a experiência de existir em sua corporeidade: desdobramentos do toque. Queremos, no entanto, aludir a mais um aspecto desenvolvido por Anzieu (1989). Trata-se de outro paradoxo da pele que consiste na dupla ação de tocar e ser tocado ao mesmo tempo. Em outras palavras, o fato de que

ao tocarmos algo, somos concomitantemente tocados por esse algo é, na obra de Anzieu, de grande importância para a futura capacidade reflexiva do Eu (assim resumida: "Eu me toco"), capacidade que aponta para algo da ordem de um 'dois em um', no qual se é sujeito e objeto de uma mesma ação (DURSKI; SAFRA, 2016, p. 108-109).

Essa dupla função do toque a que acabamos de aludir nos coloca diante do aspecto erótico que a pele contempla. "Eu me toco", alargando seu sentido, sugere o primeiro contato com o prazer erótico desenvolvido na experiência da sexualidade de cada indivíduo: a masturbação. Além disso, as noções de prazer estão imbricadas, portanto, à experiência primeira de intercorporeidade: a mãe (ou substitutos) e o bebê, num momento inicial da vida; e, depois, a experiência com o Outro, que ajudará na construção de si mesmo. Dentro desse paradoxo, podemos pensar a economia geral do gozo para o sujeito. A duplicidade dessa ação é também desdobrada por Merleau-Ponty no curso do Collège de France, que confere às superfícies tocante e tocada do corpo o status de sujeito:

quando toco minha mão esquerda com minha mão direita, minha mão tocante apreende minha mão tocada como uma coisa. Mas, de súbito, dou-me conta de que minha mão esquerda começa a sentir. As relações se invertem. [...] Como coisa física, ela continua sendo sempre o que é e, no entanto, é diferente segundo for tocada ou tocante. Assim eu me toco tocando, realizo uma espécie de reflexão, de cogito, de apreensão de si por si. Em outras palavras, meu corpo 
torna-se sujeito: ele se sente (MERLEAU-PONTY, 1995, p. 107-108 apud MANZI FILHO, 2007, p. 45-46).

Durante o século XIX, como aponta Birman (1999, p. 31), a sexualidade era concebida com o único objetivo de reprodução da espécie, ideia também sedimentada pela sexologia. Na contramão dessa concepção, Sigmund Freud precisou demonstrar que "o sexual tem uma pluralidade de objetos possíveis" (BIRMAN, 1999, p. 32), deslocando assim o lugar protagonista da genitália no prazer e gozo dos sujeitos. Enunciar o polimorfismo da sexualidade foi um primeiro passo para a elaboração de uma cartografia sexual do corpo que, inclusive, considerava outras práticas sexuais que não desembocassem em reprodução. Houve, assim, o resgate de uma geografia que considera, então, a pele como potente órgão de revestimento:

Esses diferentes lugares, constitutivos da geografia erótica do corpo, foram denominados por Freud zonas erógenas. Essas seriam regiões localizadas na superfície do corpo que fazem fronteira com a exterioridade deste e que se contatam com outros corpos. Assim, as zonas erógenas seriam os lugares privilegiados onde se estabeleceriam as relações intrincadas entre o dentro e o fora do corpo, indicando, pois, a porosidade corporal (BIRMAN, 1999, p. 32).

A pele, desse modo, interliga e posiciona-se numa zona fronteiriça. Ainda a respeito do caráter de divisa da pele, ela "separa e une", diz Anzieu, "os diferentes sensórios. Tem [...] um papel de intermediária, de entremeio, de transicionalidade." (1989, p. 33). Convergindo aqui as proposições de Anzieu - o Eu-pele - e as de Freud, explicitadas por Birman (1999), a estruturação do eu precisa ser processada no corpo, bem como o seu prazer e a construção da sua sexualidade, que é polimorfa em função da geografia erótica ser dispersa pelo corpo revestido em pele: "o ego é 
antes de tudo corporal, sendo pois um eu encorpado e incorporado num corpo. Não existiria então eu sem corporeidade, sendo ele também sexual, alheio, portanto, a qualquer construção ideal e às operações assépticas da razão." (BIRMAN, 1999, p. 35). De modo a endossar o papel do corpo na estruturação perceptiva do eu, retomemos a Fenomenologia da Percepção: “A percepção torna-se uma 'interpretação' dos signos que a sensibilidade fornece conforme os estímulos corporais" (MERLEAU-PONTY, 1999, p. 62). Em outras palavras, as nuances perceptivas são, de antemão, sínteses corporais.

A relação entre erotismo e pele não é uma elaboração recente, mas remonta à cultura grega - que remete ao mito de Eros e Poros, demonstrando a estreita comunhão entre eles. Retomemos o mito por meio da escrita da ensaísta Maria Cristina Franco Ferraz:

Como nos ensina o Dicionário de mitologia grega e romana de Grimal (1951), Poros, Expediente, é filho de Métis, primeira esposa de Zeus, que a engoliu por temê-la, já que se tratava da divindade que presidia à Astúcia. Como um deus cioso por garantir seu reinado, Zeus precisava se precaver contra uma esposa astuciosa. O nome de Poros foi incorporado ao vocabulário filosófico, que caracteriza como aporia (termo composto por poros acrescido do prefixo privativo grego $a-$ ) qualquer situação sem saída ou de impasse. Como filho da Astúcia, Poros é o expediente, o "jeitinho" que se vislumbra para encontrar alternativas e saídas em situações difíceis ou embaraçosas.

O mais curioso é como Poros está intimamente ligado a Eros, especialmente na versão do mito proposta pela sacerdotisa Diotima, que toma a palavra no diálogo platônico O banquete (PLATÃO, 1973). Segundo Diotima, Eros é um ser intermediário entre os deuses e os homens, fruto da união de Penia (Pobreza) com Poros. Eis a deliciosa história: não tendo sido convidada para um banquete dos deuses, Penia se aproveita do sono de Poros, que dormia saciado nos jardins, e engendra Eros, resultado portanto do enlace entre a Pobreza e o Expediente. Seguindo a sugestão, legada pelos gregos, desse íntimo parentesco entre Poros e Eros, podemos avançar a hipótese de que a despotencia- 
lização da profundidade paradoxal da pele e o bloqueio da porosidade afetam a circulação de Eros nos corpos (FERRAZ, 2014, p. 67, grifos da autora).

A porosidade da pele e seu desdobramento para o interior do corpo - conferindo volume a esse órgão - não se atrela apenas a Eros (ao erotismo, portanto); a saúde desse órgão e o tratamento que lhe direcionamos acarretam várias virtudes relacionais. Vejamos, como mero exemplo, um uso corriqueiro de linguagem ligada à pele e ao bom uso que dela se faz: se aporia, como aponta Ferraz (2014), significa uma situação sem saída, um impasse, ter tato é uma expressão que caracteriza justamente o bom manejo das capacidades para o contorno de situação desagradável. A pele, assim, exprime a zona de contato para os mais diversos tipos de relação com o Outro.

Feita essa breve digressão a fim de contextualizar a pele em âmbito de pensamento diverso, colocamos as questões pertinentes no que diz respeito à poesia de Luís Miguel Nava: a) que lugar ocupa o corpo numa poesia que tematiza o erotismo? b) que parte do corpo é privilegiada como ponto erótico?, e, finalmente, c) há deslocamento dessas partes passíveis de conter eros numa poesia que especifica o eros como homossexual? Procuraremos demonstrar, na poesia de Nava, as possíveis respostas para as indagações apresentadas; expor a reconfiguração espacial que o poeta faz, embaralhando os pares dicotômicos, a mudança da geografia erótica do corpo, destituindo a genitália de excessivo protagonismo e alocando a pele e suas relações de superficialidade e profundidade como pontos erógenos por excelência. Em outras palavras, mostrar como o poeta reconduz "o amor", como diz Anzieu, "ao contato de duas epidermes" (1989, p. 25). Queremos apenas destacar uma rasura: no lugar da palavra "amor", colocar "paixão" - palavra mais apropriada ao léxico naviano, que é construído em cima de rebentações, vísceras e entranhas: pulsões. 


\begin{abstract}
A nossa anatomia é uma terra enigmática e longínqua sobre cujo mapa jamais pensámos debruçarnos.

"A Cor dos Ossos", O Céu Sob as Entranhas.
\end{abstract}

Apesar da morte precoce, Luís Miguel Nava tem uma produção poética considerável, não apenas no quesito numérico, mas, sobretudo, na densidade da sua produção: seu primeiro livro, Películas, data de 1979, seguido de A Inércia da Deserção (1981), Como Alguém Disse (1982), Rebentação (1984), Poemas - obra de 1987 que reúne a reedição dos livros anteriores -, O Céu Sob as Entranhas (1989) e Vulcão (1994). Em 2002, foi lançada a obra Poesia Completa 1979-1994, cujo volume acopla suas publicações anteriores e é acrescido de textos inéditos. É nessa obra que o nosso trabalho está centralizado.

No conjunto da sua poética, é o corpo que funciona como eixo temático principal, orbitando todas as outras linhas de força ao redor dele. Já na sua publicação de estreia, Películas (1979), temos a apresentação de eixos norteadores que serão recuperados, ressignificados e desdobrados ao longo de sua produção. O corpo funciona como uma tela viva, "uma espécie de matriz na qual se gravam a inquietação e o tormento com que é vivida a experiência de estar no mundo.” (FERREIRA, 2009, p. 3). A impressão dessa vivência, como numa película fotográfica, fica evidente em várias partes da anatomia corporal, mas destacamos, principalmente, a pele como órgão que guarda muitas memórias: "Vem sempre dar à pele o que a memória carregou, da mesma forma que, depois de revolvidos, os destroços vêm dar à praia." (NAVA, 2002, p. 97). A respeito dessas inscrições da memória biológica dos órgãos, evidenciamos mais um paradoxo da pele: ela "protege o equilíbrio de nosso meio interno das 
perturbações exógenas, mas em sua forma, sua textura, sua coloração, suas cicatrizes, ela conserva as marcas destas perturbações.” (ANZIEU, 1989, p. 32). Desse modo, dores e prazeres são, consubstancialmente, formações da pele.

A pele, na poesia de Nava, encontra respaldo também no tratamento a outros órgãos ou composições do corpo que recorrentemente aparecem na diegese do texto: coração, intestino, sangue, vísceras. De uma carga biológica muito grande, é no sentido de recuperar os processos dos folhetos germinativos que Fernando Pinto do Amaral, no prefácio à Poesia Completa - "As cicatrizes da Lava" - dará relevo às questões ligadas ao corpo, elaborando divisões, para fins de análise, desse caráter biológico:

Em face da tensão assim gerada, gostaria ainda de chamar a atenção para os elementos corporais dominantes, tendo em conta a sua génese embriológica: vemos, então, que, das vísceras propriamente ditas (ou seja, endoblásticas), nenhuma surge individualizada com insistência, ao passo que os órgãos de origem mesoblástica (por exemplo, os ossos, o sangue e sobretudo o coração) rivalizam com os de proveniência ectoblástica (os nervos e a pele), muito convocados por esta poesia (AMARAL, 2002, p. 28, grifos do autor).

A citação das áreas biológicas demonstra, na escrita de Nava, alguma intraduzibilidade de um discurso por vezes hermético porque convocatório de uma linguagem científica, metafórica e econômica no seu manejo sintático. Recorrendo a palavras que configuram outra elaboração do que foi dito, o "discurso para o qual a poesia de Luís Miguel Nava tende", explicita Moisés David Sousa Gomes Ferreira, “é marcado pela intenção de tornar a linguagem 'árida"” (FERREIRA, 2009, p. 4). Vejamos:

Devemos, ao falar, ter o maior cuidado com as palavras que empregamos, pois, sendo algumas delas particularmente 
vulneráveis às raízes, arriscamo-nos a ver apoderar-se-nos da fala uma vegetação que talvez chegue mesmo a destruir-nos. A fala quer-se árida, de uma aridez idêntica à da roupa que nos cobre o corpo ou à do céu, de que me esforço, sempre que dele falo, por deixar à mostra um dos agrafos mais profundos (NAVA, 2002, p. 168).

Para além do referido a respeito da linguagem árida, convocada pelo poeta no poema referido, há nessa citação outro eixo temático que orbita ao redor do corpo, dele não se destaca. Fernando Pinto do Amaral avulta a atração entre corpo, órgãos e elevações (o sol, o céu, os astros) como algo de "dimensão cósmica" (AMARAL, 2002, p. 27 apud FERREIRA, 2009, p. 6) - à maneira de Ícaro, cuja elevação aos céus o aproxima do Sol e derrete as suas asas, devolvendo-o à terra num mergulho. A menção ao alto, contida na obra de Nava, serve como ponto de oposição e pretexto para o mergulho e descida na essência da carne, na profundidade e raízes do eu (AMARAL, 2002, p. 27). Em Sol subterrâneo, o sujeito poético reconfigura e embaralha o alto e o baixo, a luz e a escuridão: "O sol subterrâneo, aquele a que eu/me quero hoje estender é o do meu espírito, é preciso/ cavar bem fundo até o fazer surgir." (NAVA, 2002, p. 138).

Importa destacar o jogo de luz e sombra presente na poética naviana, cuja construção convoca, inclusive, o excesso e a violência - elementos constitutivos dos seus textos (AMARAL, 2002, p. 25). Percebemos o contrassenso ao "cavar bem fundo" para fazer surgir o Sol, inferindo que o subterrâneo é dotado de falta de luz. A esse respeito, Alberto Pucheu, no sensível ensaio sobre Luís Miguel Nava, alerta:

Às vezes, não se consegue ver por excesso de luz. Outras, por excesso de escuridão. $O$ perigoso provocador da cegueira não é, entretanto, o predomínio do excesso, mas a exclusão recíproca entre luz e escuridão. [...]. Ver é fazer a experiência ativa da unificação desses contrários, percorrer o fio que une esses extremos, borrando os isolamentos estanques. Na escuridão, vê-la também como luz, na luz, 
vê-la também como escuridão; em ambas, habituar o olhar, simultaneamente, tanto a uma luz mais forte quanto a uma escuridão mais forte. Nos poemas de Luís Miguel Nava, se, em nenhum momento, o excesso deixa de manifestar sua intensidade maior, muitas vezes o excesso de luz se encontra misturado ao excesso de escuridão (PUCHEU, 2011, p. 331).

As figuras de excesso às quais se referem tanto Alberto Pucheu quanto Fernando Pinto do Amaral são, em muitos momentos, forças da natureza elevadas ao seu máximo de capacidade violenta e destruidora: "tempestades e intempéries, ondas fortíssimas a deflagrarem nos rochedos, nas cristas das falésias, relâmpagos, incêndios, clarões e trevas, despenhadeiros, crateras escavadas, lava espessa, abismos e desertos." (MARTELO, 1998, p. 12).

À guisa do reordenamento espacial, temos ainda o título de uma das obras de Nava - O Céu Sob as Entranhas (1989) -, no qual evidenciamos uma linha de força que figura também nos poemas. Segundo Sinei Ferreira Sales, numa entrevista ao Jornal de Notícias, em 1990, a propósito do lançamento do livro referido, Nava responde ao estranhamento que a reordenação espacial do corpo, dos órgãos e dos elementos cósmicos provocou na crítica especializada à época: “Aqui o céu já não está por cima, mas por baixo ou, se se preferir, por dentro das entranhas. Assistese, portanto, a uma alteração das relações espaciais, tal como é costume concebermo-las" (NAVA apud SALES, 2018, p. 351-352).

A disposição espacial subvertida por Nava figura também nas forças naturais e, como não podemos deixar de pontuar, na própria pele. Conforme Rosa Maria Martelo:

a paisagem marítima é sempre caracterizada através do arrebatamento de um mar que se alça, que se revolve e deflagra. É o que se poderia descrever como um mar que se verticaliza, água que ascende de modo violento (ao con- 
trário do poço e do rio, marcados pela imobilidade ou pelo menos pela horizontalidade, e ainda da neve, que inverte o percurso de ascensão) (MARTELO, 1998, p. 17).

É ainda com Martelo (1998, p. 17) que destacaremos a presença da água em suas diferentes formas: como mar, presente sobretudo nos trabalhos Películas, Poemas, A Inércia da Deserção, Como Alguém Disse e Rebentação; sob a forma de rio, a água aparece em $O$ Céu Sob as Entranhas; e, finalmente, em Vulcão a água figura com mais recorrência na forma de neve ou gelo. O mar e, portanto, o reordenamento da sua posição, quando não é trazido à tessitura do texto com a violência inerente à sua natureza, verticaliza-se no corpo do rapaz, mencionado nos poemas de tônica homoerótica. No poema Ao mínimo clarão, a força e a energia, características do mar, corporificam-se no rapaz, o que, inclusive, concedelhe o direito de ser chamado "rapaz rebentação":

Talvez seja melhor não nos voltarmos a ver, ao mínimo clarão das mãos a pele se desavém com a memória. As mãos são de qualquer corpo a coroa.

Das dele já nem sequer o itinerário sei hoje muito bem, onde o horizonte se desata o mar agora regressa ao coração de que faz parte.

Ainda é o mar contudo o que se vê florir onde ele chegar. Chamando a esse rapaz rebentação, o céu rasga-se à volta dos seus ombros (NAVA, 2002, p. 88).

No que concerne à pele, Nava enfatiza seu caráter intermediário, zona de contato entre o fundo e o raso: 


\section{A VÁRIOS METROS DE PROFUNDIDADE}

Quem como eu não sentiu já no corpo um dos seus órgãos a afundar-se? Sentir nele os brônquios, por exemplo, ou o fígado, o intestino, a vários metros de profundidade torna-nos, entre outras coisas, impacientes. Mais, contudo, quando a pele, que com eles sonha, devagar no-los espelha, subterrânea" (NAVA, 2002, p. 96).

Ou ainda:

\section{O ABISMO}

Com a sua pele de poço, pele comprometida com o medo que no fundo fede e a que, digamos, toda ela adere de uma forma resoluta, dir-se-ia que se engancha, se pendura, o branco da memória a alastrar pelo corpo, um branco tão branco como o das noites em branco e sobre o qual a idade, exorbitada, hiante, se insinua, pensos, ligaduras, impregnados de memória, uma memória onde fulgura a lava dos sentidos que entram em actividade e lhe disputam os dias idos, assim ergue a balança, onde sustém o abismo (NAVA, 2002, p. 249).

A pele-poço e subterrânea denota quer a relação dicotômica luzescuridão, quer a realocação de materialidades, subvertendo os pares e sua coerência. Em Nava (2002, p. 163), a criação de uma "pele metida/ consigo mesma e que servia/ de poço" também nos serve como "dissolução de dicotomias", conforme Martelo (1998, p. 14). Sem querermos esgotar as possibilidades da poética naviana no que diz respeito à profundidade da pele e seu reordenamento, cabe apenas mais um exemplo, o poema $O$ 
Polvo, o qual ilumina a relação essencial entre superfície e profundidade e no que aquela espelha esta, numa dinâmica de raiz, que metonimicamente recorre às plantas: “[...] Ao unir-se assim às mais variadas épocas, a pele vai aos poucos adquirindo a configuração dum polvo, o qual, como se sabe, é de todos os animais o que mais se assemelha a uma raiz." (NAVA, 2002, p. 172).

Em relação à figura do rapaz (desdobrada, às vezes, em rapazes ou amigo), ela condensa muitas linhas temáticas já levantadas aqui: é um "rapaz rebentação" que traz consigo a verticalidade do mar (2002, p. 88); a violência do mar "está-lhes na pele" (2002, p. 95); esse rapaz "que pelo interior/de cuja pele o sol surge antes de o fazer no céu" (2002, p. 86), deslocando luz e sombras e embaralhando dicotomias (NAVA, 2002, p. 88; p. 95 ; p. 86 , respectivamente).

No dicionário Michaelis, "rapaz" deriva do latim rapacem e seu sentido etimológico está atrelado, como adjetivo, a quem rouba - rapace, rapinante (MICHAELIS, 2020). Como substantivo masculino, há também o sentido primário de indivíduo que rouba. Embora as acepções tenham caído em desuso, não é alheio mencionar, se levarmos em conta as condições da morte de Luís Miguel Nava, que morreu pasolinicamente. Aqui, no entanto, levaremos em consideração o vocábulo "rapaz" como sinônimo de "homens jovens".

É evidente que estamos diante de um eros notadamente homossexual, vivenciando no corpo as pulsões de desejo e gozo. Contudo, esse corpo, à revelia de outros poetas, não realiza a escrita pautada em beijos e carícias, como bem salienta Amaral (2002, p. 26): o "fulgor erótico deste discurso atravessa, no entanto, as fronteiras temáticas mais previsíveis e contamina tudo o que se relaciona com o corpo, abrindo um território de leitura quase inesgotável”. Retirando Luís Miguel Nava de um erotismo tratado de maneira evidente e, em alguma medida, banal, Amaral (2002, p. 26) conclui: "Para este poeta, o mais indelével resulta de um 
irresistível desejo de se expor até ao âmago, até às vísceras."

Indo em direção à proposição de Amaral, Alberto Pucheu destaca o caráter de um corpo que se imbrica com tudo e se espraia em toda a gama de assuntos que diz respeito à existência. A essa relação do homem com o mundo, submetida ao filtro do eros homossexual de Nava, Pucheu dá o nome de cosmoerotismo.

Importante frisar que, se há uma efervescência homoerótica nos poemas de Nava, seu erotismo se dá, sobretudo, por todo e qualquer modo de o homem se relacionar com o mundo, havendo, prioritariamente, um cosmoerotismo em sua poesia. Nela, o homoerotismo - que existe e ajuda a compor alguns de seus mais belos poemas - está submetido, enquanto passagem, ao cosmoerotismo (PUCHEU, 2011, p. 337).

Embora o homoerotismo na poesia de Nava nem sempre nomeie a descontinuidade - boca, ânus, cavidades -, fazendo menção à superfície de lisura (pele), discorremos, até aqui, contra-argumentos para entender a porosidade da pele como canais de abertura e incompletude do ser. Assim, o desejo e o erótico marcados pela fricção existente em duas ou mais epidermes que se encostam. A porosidade - recordemos o mito que filia Eros a Poros - é, então, a marca de uma falta que abre espaço para o preenchimento. Nas palavras de Joel Birman, explicitando o pensamento de Freud, "[s]eria então a incompletude do corpo e do sujeito que empurraria este de maneira fatal para os braços do outro, pois precisa desse outro de forma inapelável para a experiência da satisfação e do gozo" (BIRMAN, 1999, p. 35). É esse outro, o rapaz, que passa pelos poros do sujeito poético, preenchendo a ausência com gozo e mar: 
O mar, venho ver-lhe a pele a rebentar ao longo das falésias, o que sempre me traz a exaltação desses rapazes que circulam por Lisboa no verão.

O mar está-lhes na pele. Partilho com eles os quartos das pensões, sentindo as ondas a avançar entre os lençóis. Perco-me à vista da pedra onde o mar vem largar a pele (NAVA, 2002, p. 95).

Cabe aqui ressaltar que a pele, conforme Pucheu (2011, p. 337), submete "o indivíduo ao cosmogônico, fazendo-o passar, liquidificado ou eletrificado, pelas frestas de seus poros em que se abrem os espaços do pensamento". Liquidificado porque, como já vimos, a água, principalmente na figura do mar, é recorrente nessa poesia que assemelha superfícies num jogo metafórico e metonímico - pele, mar, espelho, lençol - como no poema $\mathrm{Na}$ Gávea em que pele e mar são colocados com valores similares: "Ocorre-me de vez em quando a ideia de que o homem que nos barcos sobe à gávea o faz na realidade apenas para perscrutar a sua própria pele [...]" (NAVA, 2002, p. 108). Quanto ao indivíduo eletrificado, temos, em Ars Poetica um poema prototípico de elementos de força e violência recorrentes nessa poética: o mar, já referido, e os relâmpagos - "O mar, no seu lugar pôr um relâmpago" (NAVA, 2002, p. 44). A colocação de um relâmpago na superfície do mar - sua pele, arriscamos dizer - sugere um rasgo nessa lisura, criando fendas, ainda que de pouca duração, para a introjeção do desejo, a porosidade que estabelece a falta e, por isso mesmo, a busca para saciá-la. Em relação ao poema Ars Poetica, Sinei Ferreira Sales (2018, p. 356) destaca dois polos, um ativo e outro passivo: o "mar é mais do que passivo, pois ele não apenas recebe a ação, como afeta. Ainda que para acessá-lo seja necessário adentrá-lo, senti-lo, ser afetado, isso só é possível pela pele e pela visão". 
Num outro poema de Nava, Através da Nudez, temos mais uma imagem violenta, porém bela a respeito do rapaz, neste caso denominado de garoto, inferindo a rasura que ele pode cometer na superfície: "Este garoto é fácil compará-lo a um campo de relâmpagos/ encarcerando um touro. Através da nudez vêem-se os/ astros." (NAVA, 2002, p. 46). Retomamos aqui a importância da luminosidade como maneira de evidenciar a cena, enfatizar algo na paisagem: "um campo de relâmpagos encarcerando um touro" é a referência para pensarmos a potência do garoto e, consequentemente, o teor erótico da imagem. Um segundo caráter deste poema destacado por Sales (2018) é o uso dos dêiticos. Sales recupera os poemas Onde à Nudez, Através da Nudez e a obra O Céu Sob as Entranhas para marcar a topografia espacial naviana (SALES, 2018, p. 357-358). Além dos dêiticos presentes nos títulos, "Este garoto", palavras do primeiro verso, para Sales, também apresenta três possibilidades de leitura, que são descartadas assim que o poema é desdobrado:

Primeiro, poderia marcar um garoto que estivesse próximo ao sujeito que se enuncia tanto fisicamente, quanto presentificado pela memória; poderia ser lido também enquanto autorreferência ao sujeito, bem como poderia representar uma referência ao poeta. (...) Essa figura incerta que representa o garoto começa a desnudar sua origem na segunda estrofe. É ela o fruto da memória: o uso de 'este' marca a proximidade do sujeito que se enuncia e a reminiscência da figura do garoto cujo sexo torna-se uma forma de conhecer (SALES, 2018, p. 358-359).

Retomando nossas proposições acerca da porosidade da pele, Sales destacará no poema Ars Erotica - "Eu amo assim: com as mãos, os intestinos. Onde ver deita folhas." (NAVA, 2002, p. 43) - a referência, um tanto hermética, ao ânus - a fissura da falta na lisura da pele. $\mathrm{O}$ autor do ensaio "Apontamentos para uma poética queer: uma leitura da poesia de Luís Miguel Nava" dará relevo a três aspectos do poema, atitude que nos interessa porquanto sua análise arguta dialoga com a nossa intenção neste 
artigo. São eles: eros, physis e poiesis:

As cesuras mais evidentes separam eros (amor) e physis (mãos e intestinos) da materialidade da poiesis (folhas [do poema]). Uma estratificação que limita o enunciável e o visível, mas que denota de forma bastante clara quais os fins do Amor (SALES, 2018, p. 347).

Explicitamente amar com as mãos remete ao tato e, portanto, à pele. Amar com os intestinos figura, especificamente nesse poeta, o ato sexual homossexual. Por fim, "Onde ver deita folhas" acrescenta o olhar à satisfação do desejo pelo toque. Temos, nesse verso, a relação entre desejo e linguagem, numa fricção de superfícies (da mão e da folha) para a criação da escrita. Em outros termos, "[t]odo o contacto, para o enamorado" - aqui evocamos uma relação de pathos com a escrita - "coloca a questão da resposta: pede-se à pele que responda." (BARTHES, 1981, p. 56).

De acordo com Roland Barthes, a linguagem possui uma zona de contato, tátil, que é friccionada com outra superfície também sensível e receptiva a esse toque. Notemos, na escolha vocabular do autor, um desdobramento da pele transferida para outros formatos:

A linguagem é uma pele: esfrego minha linguagem no outro. É como se eu tivesse palavras ao invés de dedos, ou dedos na ponta das palavras. Minha linguagem treme de desejo. A emoção de um duplo contacto: de um lado, toda uma atividade do discurso vem, discretamente, indiretamente, colocar em evidência um significado único que é 'eu te desejo', e liberá-lo, alimentá-lo, ramificá-lo, fazê-lo explodir (a linguagem goza de se tocar a si mesma); por outro lado, envolvo o outro nas minhas palavras, eu o acaricio, o roço, prolongo esse roçar, me esforço em fazer durar o comentário ao qual submeto a relação (BARTHES, 1981, p. 64).

Decerto, a poesia de Nava possui um caráter metapoético, já 
evidenciado por Amaral (2002, p. 20-21), que dialoga com todo o léxico do excerto de Barthes, deixando-nos mais convencidos de que a "pele de fato é semelhante às páginas de um livro, pois são elas superfícies de inscrição que possibilitam zonas de visibilidades." (SALES, 2018, p. 353). No poema Final, o sujeito pede que o leitor acolha bem o livro que lhe chega às mãos, perscrutando um trabalho de elaboração corpo a corpo, citando as superfícies e dando relevo à relação tátil com o objeto de linguagem finalizado.

\footnotetext{
Não foi sem dificuldades que este livro rompeu através dos interstícios do mundo até chegar às tuas mãos, leitor, para aí, como um deserto a abrir noutro deserto, criar uma irradiação simbólica, magnética, onde o branco do papel e o negro das palavras, essas cores que segundo Borges se odeiam, pudessem fundir-se e converter-se nessa outra a que, na enigmática expressão de Sá-Carneiro, a saudade se trava. Como um desses objectos cujo peso, assim que neles pegamos, instantaneamente se divide entre as nossas mãos e a alma, é mesmo de crer que ele esteja já dentro de $t i-\mathrm{e}$ algo de mim com ele. Acolhe-o, pois, com benevolência, que, chegada a altura, havemos de arder juntos (NAVA, 2002, p. 265, grifos nossos).
}

A mesura pedida, a introjeção do livro "dentro de ti” após sensação de sentir o peso do objeto, pegá-lo, ações proporcionadas pelo tato confluem para o entendimento de uma profundidade alcançada, primeiramente, pela superfície que intermedeia e conecta. Ainda na esteira da pele e da escrita, numa relação de atração mútua, Pucheu relaciona o labor do poeta à abertura dos poros, aproximando a folha da pele e conferindo à sua lisura branca qualidades de porosidade desse grande órgão que a todos reveste: "[e]screver é, assim, cavar, ampliando a porosidade por onde a realidade transita, transcrevendo sempre a porosidade" (PUCHEU, 2011, p. 339). Os dizeres de Pucheu não deixam de estar de acordo com o que Ferreira considera acerca do corpo na poética naviana: “o corpo, em Nava, 
funciona como uma espécie de núcleo para o qual conflui a densidade de todas as experiências existenciais" (FERREIRA, 2009, p. 6). Corpos de carne - também vísceras! - e de texto convergindo para a transcrição da porosidade na poesia de Luís Miguel Nava.

$* * *$

Apele enquanto superfície ocupa um lugar crucial para o intercâmbio de vários aspectos da realidade e subjetividade na penetração do corpo. Ela é nosso meio de comunicação primário, como atesta Ferraz (2014), à frente inclusive da fala. É na gênese da pele, em contato com o mundo (o Eu-pele), que elaboramos nosso eu psíquico, relação explorada por Anzieu (1989), também exposta - a comunhão superfície e profundidade - por Gil (1997; 2001 apud FERRAZ, 2014), que recupera a sensação do toque, sentido milímetros abaixo da epiderme, para argumentar a favor de um para dentro que a pele resguarda, levando mesmo o filósofo a nomear esse mergulho como volume, isto é, a pele estabelece uma relação de volume consigo mesma e com os demais órgãos. Resgatando também a ideia de que o corpo precisa estar situado, Merleau-Ponty (1999) cria o conceito profundidade para a relação que o corpo mantém com o espaço, ou seja, estar situado espacialmente é ter perspectiva, ver o mundo de um lugar específico. Além dessa elaboração acerca da pele em diferentes áreas do conhecimento, inserimo-la também na cartografia do erótico como um dos principais órgãos a potencializar e permitir o prazer e o gozo do sujeito, proposições trazidas à baila através do trabalho de Birman (1999).

Exposta a relevância desse órgão em vários âmbitos, entramos na poesia de Luís Miguel Nava, que centraliza a pele como um órgão de contato não apenas com a realidade da qual obstinadamente se ocupa em traduzir na escrita, mas também como ponte entre o externo e o interno, entre o dentro e o fora, entre o raso e o fundo (do corpo), entre o eu e o outro. No 
seu projeto de escrita, Nava (2002) embaralha os pares dicotômicos, e seus poemas parecem reforçar a célebre frase de Paul Valéry (apud SALES, 2018 , p. 353), que diz ser a pele o que de mais profundo temos. Numa poesia que convoca as vísceras, o sangue, as entranhas para figurarem na diegese, a pele ocupa lugar privilegiado.

A pele na obra de Nava relaciona-se, ainda, com outras imagens de violência e beleza que também possuem suas superfícies em dialogia com suas profundidades: o mar, o espelho, a folha em branco, por exemplo. Subvertendo os seus lugares de origem, Nava também reposiciona materialidades e elementos cósmicos: o céu é rebaixado, o sol introjetado, a pele torna-se subterrânea, o mar verticaliza-se. Juntamente com esses elementos citados, o eros, notadamente homossexual, aparecerá na figura do rapaz - com variações: rapazes, garoto - e terá na pele o motivo do desejo: um rapaz rebentação que carrega o mar na pele e o larga no lençol do sujeito lírico. Uma poesia que convoca o corpo e desdobra as diversas nuances que dele fazem parte: um corpo que ora se expande, captando, através da porosidade, realidades exógenas; ora se retrai e fica imbricado consigo mesmo, elucubrando sua composição de sangue, vísceras e carne.

Procuramos, neste trabalho, desdobrar hipóteses sobre a pele por meio de rápidas digressões que validam nossos argumentos, além de tentar responder às questões postas ao longo do trabalho: como a que indaga o lugar do corpo na poesia erótica, ou a que problematiza a parte do corpo que é privilegiada como máxima contenção de erotismo, ou, ainda, a que interroga qual a configuração do corpo numa poesia que tematiza um eros explicitamente homossexual. Tentamos responder às questões - ou, no mínimo, ajudar a dar mais qualidade às perguntas -, recorrendo à poesia de Luís Miguel Nava.

\section{Referências:}


AMARAL, Fernando Pinto do. As cicatrizes da lava (Prefácio). In: NAVA, Luís Miguel. Poesia Completa 1979-1994. Lisboa: Publicações Dom Quixote, 2002.

ANZIEU, Didier. $O$ eu-pele. Tradução de Zakie Yazigi e Rosali Mahfuz. São Paulo: Casa do Psicólogo, 1989.

BARTHES, Roland. Fragmentos de um discurso amoroso. Tradução de Hortênsia dos Santos. Rio de Janeiro: F. Alves, 1981.

BIRMAN, Joel. Cartografias do feminino. São Paulo: Editora 34, 1999.

DURSKI, Ligia Maria; SAFRA, Gilberto. O Eu-pele: contribuições de Didier Anzieu para a clínica da psicanálise. Reverso, Belo Horizonte, v. 38, n. 71, p. 107-114, jun. 2016.

FERRAZ, Maria Cristina Franco. Estatuto paradoxal da pele e cultura contemporânea: da porosidade à pele-teflon. Galáxia, São Paulo, n. 27, p. 61-71, jun. 2014.

FERREIRA, Moisés David Sousa Gomes. Luís Miguel Nava e o espaço do corpo em O Céu Sob as Entranhas. Nau Literária, Porto Alegre, v. 5, n. 01, jan./jun. 2009.

MANZI FILHO, Ronaldo. Em torno do corpo próprio e sua imagem. 2007. 189 f. Dissertação (Mestrado em Filosofia) - Faculdade de Filosofia, Letras e Ciências Humanas, Universidade de São Paulo, São Paulo, 2007.

MARTELO, Rosa Maria. O mar no conjuntivo e a fulguração sublime - nexos a partir da poesia de Luís Miguel Nava. Relâmpago. Lisboa: Fundação Luís Miguel Nava, n. 3, out. 1998, p. 11-20.

MERLEAU-PONTY, Maurice. Fenomenologia da Percepção. Tradução de Carlos Alberto Ribeiro de Moura. São Paulo: Martins Fontes, 1999.

RAPAZ. In: Dicionário Michaelis. Rio de Janeiro: Melhoramentos, 2020. Disponível em: https://michaelis.uol.com.br/moderno-portugues/busca/ 
portugues-brasileiro/rapaz/. Acesso em: 31 jan. 2020.

NAVA, Luís Miguel. Poesia Completa 1979-1994. Lisboa: Publicações Dom Quixote, 2002.

PUCHEU, Alberto. Alguns motivos pelos quais não consigo fugir dos poemas de Luís Miguel Nava. In: ALVES, Ida; MAFFEI, Luís. (Org.). Poetas que interessam mais: leituras da poesia portuguesa pós-Pessoa. Rio de Janeiro: Beco do Azougue, 2011, p. 331-350.

SALES, Sinei Ferreira. Apontamentos para uma poética queer: uma leitura da poesia de Luís Miguel Nava. Via Atlântica, São Paulo, n. 33, p. 343364, jun. 2018.

Recebido em: 31/05/2020

Aprovado em: 04/07/2020 